\title{
RANCANG BANGUN PROTOTIPE PENGAMAN RUANGAN DENGAN INPUT KODE PIN DAN MULTI SENSOR BERBASIS MIKROKONTROLLER
}

\author{
Aries Kamolan ${ }^{1}$, Limbran Sampebatu ${ }^{2}$ \\ ${ }^{12}$ Jurusan Teknik Elektro, Fakultas Teknik, Universitas Atma Jaya Makassar \\ E-mail: arieskamolan@gmail.com ， elsampebatu@gmail.com
}

\begin{abstract}
ABSTRAK
Penelitian ini menyediakan sistem pengaman ruangan yang berbasis mikrokontroler. Mikrokontroller ini dipakai untuk mengontrol pengamanan ruangan yang menggunakan akses kode pin sehingga hanya orang tertentu yang mengetahui kode PIN tertentu dapat masuk dalam ruangan tersebut tanpa alarm berbunyi. Dengan mikrokontroller yang sama, sistem keamanan ruangan dapat ditingkatkan dengan menambah dua jenis sensor yaitu sensor yang peka terhadap tubuh manusia (PIR) dan sensor yang dapat mendeteksi Api. Sistem pengaman ruangan ini dirancang dengan tiga kondisi yang akan aktif secara pararel. Jika satu atau lebih kondisi terpenuhi maka alarm berbunyi sebagai tanda bahwa ruangan dalam keadaan tidak aman. Hasil simulasi sesuai rancangan bahwa alarm berbunyi jika sesorang berada dalam ruangan tanpa menonaktifkan sistem atau ada nyala api dalam ruangan tersebut. Rancang Bangun Prototipe Pengaman Ruangan Dengan Kode PIN dan Multi Sensor Berbasis Mikrokontroller dapat menjadi model sistem pengaman ruangan yang mempunyai tingkat keamaman yang lebih baik.
\end{abstract}

Kata Kunci : mikrokontroller arduino, sensor PIR, sensor api, keypad, buzzer

\begin{abstract}
ABSTRACK
This research design a sistem to provide room security based on micro-controller. This research designs a system to secure a specific room using a specific code number for that only specific persons have the access to the secured room otherwise the alarm will on as a notification that inappropriate person try to enter the secured room. To enhance the security of the specific room, this research also added two others sensors; PIR sensor and fire sensor. The security system able to activates three conditions simultaneously. When the micro-controller find that one or more conditions meet the requirements, it will activate the alarm. The simulation results show that the alarm activate if somebody enter the room without deactivated the system or the system detects fire spot in the room.
\end{abstract}

Keywords : Microcontroller, arduino, PIR sensor, fire sensor, keypad, buzzer

\section{PENDAHULUAN}

Setiap manusia yang mempunyai harta benda atau benda berharga lainnya mendambakan sebuah ruangan yang aman untuk menyimpan harta benda mereka. Tidak sedikit dari mereka menggunakan jasa bank atau semacamnya untuk menyimpan barang berharga hanya untuk menghindari pencurian atau perampokan. Saat ini pada umumnya manusia mengamankan sebuah ruangan dengan menggunakan sistem penguncian manual atau konvensional. Namun tingkat keamanan dengan sistem ini tidak terlalu terjamin karena kuncinya bisa di duplikat, pintu dapat dibuka paksa atau pencuri dapat masuk ruangan tidak melaui pintu. Dengan berkembangnya teknologi mikrokontroller saat ini, sistem keamanan dapat dilakukan dengan menggunakan alat elektronik sebagai pengganti sistem keamanan kunci konvensional. Dengan menggunakan akses kode pin, hanya pemilik ruangan yang dapat mengontrol bunyi alarm dalam ruangan tersebut dengan cara memasukkan kode pin tertentu.

Dengan menggunakan mikrokontroller yang sama, sistem pengamanan ruangan dapat ditingkatkan dengan menambah sensor yang peka terhadap tubuh manusia, sensor yang dapat mendeteksi nyala api dan alarm. Alarm akan berfungsi jika seseorang masuk ruangan tersebut tanpa terlebih dahulu menonaktifkan sistem melalui keypad atau salah satu dari dua sensor tersebut berhasil mendeteksi tubuh manusia atau api. Penelitian ini menganalisis bagaimana 
membuat sistem pengaman ruangan yang pengontrolannya dilakukan dengan menginput kode pin dan menggunakan multi sensor dan juga merancang bagaimana mengaktifkan alarm apabila terjadi kondisi-kondisi yang tidak diinginkan. Sehingga penelitian ini hendak membuat sistem pengaman ruangan yang pengontrolannya dilakukan dengan menginput kode pin dan yang didukung oleh respon dari sensor yang peka terhadap tubuh manusia dan nyala api yang mengaktifkan alarm jika ruangan dalam keadaan tidak aman. Penelitian ini juga mengharapkan mampu menghasilkan sebuah sistem yang dapat meningkatkan keamanan suatu ruangan yang berbasis mikrokontroller.

Mikrokontroler adalah suatu keping IC dimana terdapat mikroprosesor dan memori program (ROM) serta memori serbaguna (RAM), bahkan ada beberapa jenis mikrokontroler yang memiliki fasilitas ADC, PLL, EEPROM dalam satu kemasan. Penggunaan mikrokontroler dalam bidang kontrol sangat luas dan populer. Ada beberapa vendor yang membuat mikrokontroler diantaranya Intel, Microchip, Winbond, Atmel, Philips, Xemics dan lain - lain. Dari beberapa vendor tersebut, yang paling populer digunakan adalah mikrokontroler buatan Atmel.

Arduino Uno adalah piranti mikrokontroler menggunakan ATmega328. Arduino Uno memiliki 14 Pin input/output digital (dimana 6 pin dapat digunakan sebagai output PWM), 6 input analog, $16 \mathrm{MHz}$ osilator kristal, koneksi USB, jack power, ICSP header, dan tombol reset.

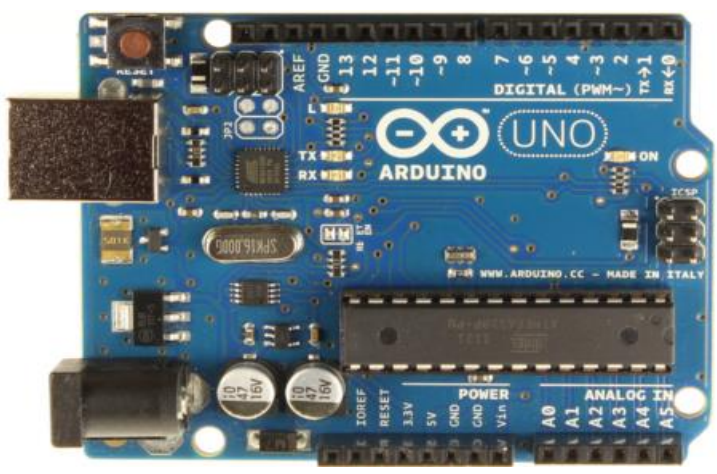

Gambar 1. Arduino Uno

Arduino juga mempunyai compiler sendiri, bahasa pemrograman yang dipakai adalah $\mathrm{C}$ atau $\mathrm{C}++$ tetapi sudah menggunakan konsep pemrograman berbasis objek atau OOP (Object Oriented Programing). Compilernya pun bersifat gratis, dan dapat diunduh di website www.arduino.cc. Kelebihan lain dari compiler arduino ini adalah dia bersifat cross-platform atau dapat berjalan di semua operating system, sehingga pengguna Windows, Linux, ataupun Mac bisa menggunakan Arduino ini.

\section{Sensor PIR (Passive Infra Red)}

PIR (Passive Infrared Receiver) merupakan sebuah sensor berbasiskan infrared. Akan tetapi, tidak seperti sensor infrared kebanyakan yang terdiri dari IR LED dan fototransistor. PIR tidak memancarkan apapun seperti IR LED. Sesuai dengan namanya 'Passive', sensor ini hanya merespon energi dari pancaran sinar inframerah pasif yang dimiliki oleh setiap benda yang terdeteksi olehnya. Benda yang bisa dideteksi oleh sensor ini biasanya adalah tubuh manusia karena adanya IR Filter yang menyaring panjang gelombang sinar inframerah pasif. IR Filter dimodul sensor PIR ini mampu menyaring panjang gelombang sinar inframerah pasif antara 8 sampai 14 mikrometer, sehingga panjang gelombang yang dihasilkan dari tubuh manusia yang berkisar antara 9 sampai 10 mikrometer ini saja yang dapat dideteksi oleh sensor. 


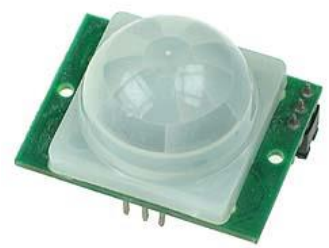

Gambar 2. Sensor PIR (Passive Infra Red)

\section{Sensor Api}

Sensor api merupakan sensor yang dapat mendeteksi nilai intensitas nyala api berdasarkan pada panjang gelombang cahayanya, yaitu pada 760nm-1100nm dengan menggunakan photo transistor sebagai komponen utamanya. Secara umum prinsip kerja dari sensor api ini adalah api dapat dideteksi berdasarkan keberadaan spektrum cahaya infrared maupun ultraviolet, kemudian sensor akan bekerja untuk membedakan spektrum cahaya yang terdapat pada api yang terdeteksi tersebut.

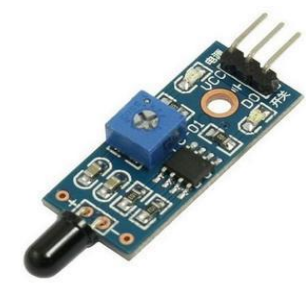

Gambar 3. Sensor Api

\section{Buzzer /Alarm}

Buzzer adalah sebuah komponen elektronika yang berfungsi untuk mengubah getaran listrik menjadi getaran suara. Pada dasarnya prinsip kerja buzzer hampir sama dengan loud speaker, jadi buzzer juga terdiri dari kumparan yang terpasang pada diafragma dan kemudian kumparan tersebut dialiri arus sehingga menjadi elektromagnet, kumparan tadi akan tertarik ke dalam atau keluar, tergantung dari arah arus dan polaritas magnetnya, karena kumparan dipasang pada diafragma maka setiap gerakan kumparan akan menggerakkan diafragma secara bolak-balik sehingga membuat udara bergetar yang akan menghasilkan suara. Buzzer biasa digunakan sebagai indikator bahwa proses telah selesai atau terjadi suatu kesalahan pada sebuah alat (alarm).

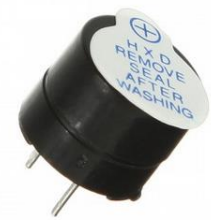

Gambar 4. Buzzer

\section{Keypad 4x4}

Keypad sering digunakan sebagi suatu input pada beberapa peralatan yang berbasis mikroprosessor atau mikrokontroller. Keypad adalah bagian penting dari suatu perangkat elektronika yang membutuhkan interaksi manusia. Keypad berfungsi sebagai interface antara perangkat (mesin) elektronik dengan manusia atau dikenal dengan istilah HMI (Human Machine Interface). Matrix keypad $4 \times 4$ ini merupakan salah satu contoh keypad yang dapat digunakan untuk berkomunikasi antara manusia dengan mikrokontroler. Matrix keypad $4 \times 4$ memiliki konstruksi atau susunan yang simple dan hemat dalam penggunaan port mikrokontroler. 


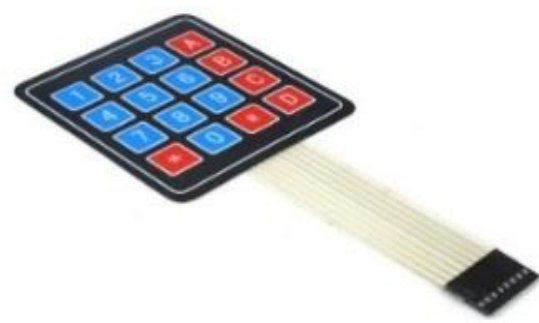

Gambar 5. Keypad 4x4

\section{METODE PENELITIAN}

Penelitian ini membuat desain sebuah sistem keamanan ruangan dengan input kode pin dan input dari sensor PIR dan sensor api. Adapun blok diagram dari sistem pengaman ini ditunjukkan pada Gambar 6.

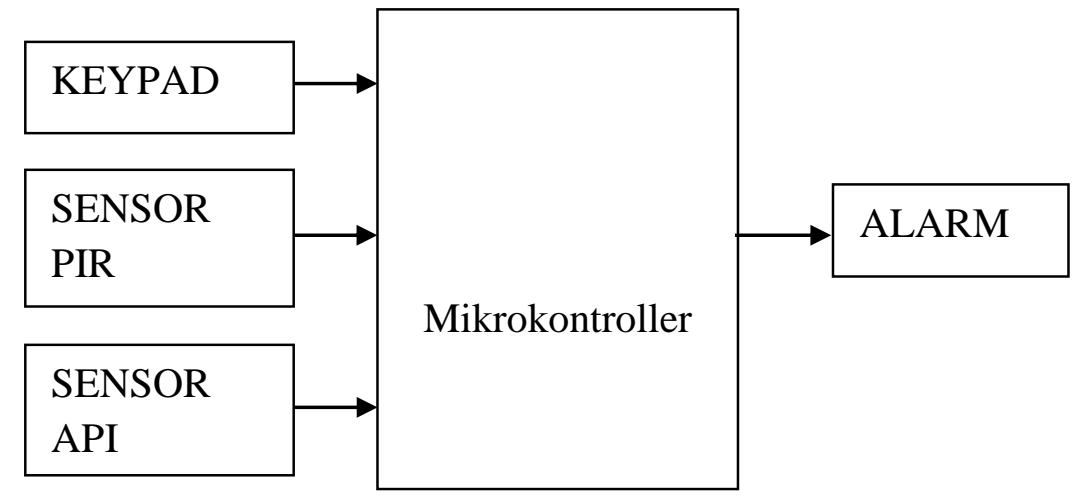

Gambar 6. Blok Diagram Pengaman Ruangan

Gambar 6 memperlihatkan bahwa input dari keypad, sensor PIR, dan sensor API ke mikrokontroller akan mengakibatkan alarm akan berbunyi atau tidak. Pada saat kode PIN ditekan pada keypad maka sensor PIR yang peka terhadap tubuh manusia akan segera mendeteksi adanya orang maka dengan sendirinya akan aktif. Alarm akan berbunyi jika seseorang berada dalam ruangan tersebut. Tetapi alarm akan berbunyi secara otomatis apabila sensor api mendeteksi adanya api walaupun keypad dalam kondisi aktif ataupun nonaktif. Untuk penggantian password atau PIN hanya dapat dilakukan pada saat pintu dalam keadaan terbuka.

Berdasarkan kerangka pikir di atas maka dibuat sebuah flowchat yang akan menjadi pedoman untuk perancangan perangkat lunak dari sistem pengaman ruangan yang akan di teliti. Flowchart dari sistem ini dapat dilihat pada Gambar 7. 


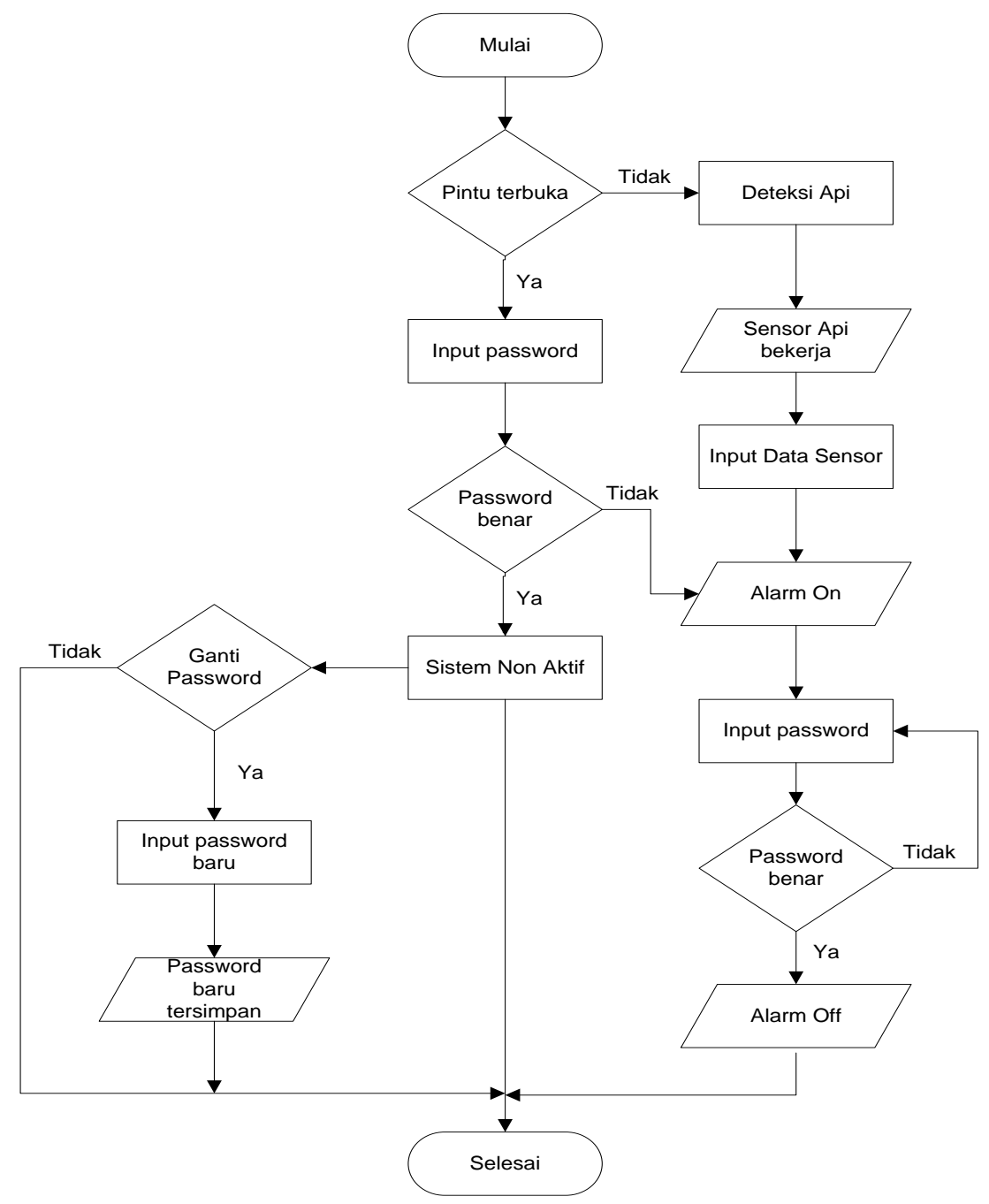

Gambar 7. Flowchart sistem pengaman ruangan

\section{HASIL DAN PEMBAHASAN}

Pada penelitian ini, digunakan Arduino IDE sebagai perangkat lunak yang merupakan sebuah aplikasi tanpa bayar dari Arduino untuk membuat list program system pengaman ruangan. Selain untuk membuat list program, Arduino IDE digunakan untuk mengunggah program yang telah dibuat ke board Arduino Uno juga sebagai framework monitoring keadaan dari sistem pengaman ruangan.

Gambar rangkaian dari perangkat keras yang akan diimplementasikan untuk membuat prototipe sistem pengaman ruangan terlebih dahulu dihubungkan satu persatu terhadap mikrokontroller agar dapat dipastikan bahwa baik perangkat keras dan perangkat lunaknya sudah terkoneksi dengan baik dan masing-masing sensor sudah berfungsi dengan baik pula. 


\section{Rangkaian Arduino dengan Buzzer}

Modul buzzer yang digunakan terdiri atas dua pin, dalam hal ini pin + dan pin GND (ground). Pin + dihubungkan dengan pin 10 pada board arduino dan pin GND (ground) buzzer dihubungkan dengan pin GND (ground) board arduino.

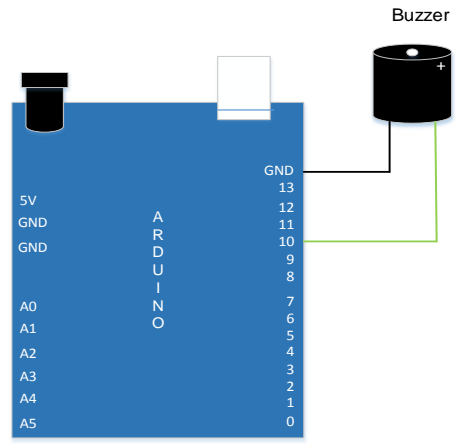

Gambar 9. Rangkaian Buzzer dengan Board Arduino Uno

\section{Pengujian buzzer}

Pengujian untuk modul buzzer bertujuan untuk mengetahui apakah buzzer bunyi jika diberi tegangan.

Tabel 1. Pengujian tegangan Buzzer

\begin{tabular}{ll}
\hline Tegangan (volt) & Alarm \\
\hline 0,004 & Tidak Bunyi \\
\hline 1,435 & Bunyi \\
\hline
\end{tabular}

Dari hasil pengujian pada Tabel 1 dapat dilihat bahwa jika tegangan mendekati 0 volt maka buzzer tidak bunyi dan jika tegangan 1,435 volt maka buzzer akan bunyi. Ini sudah sesuai dengan spesifikasi buzzer bahwa buzzer akan bunyi jika diberi tegangan minimal 1,3 volt.

\section{Rangkaian Arduino dengan Sensor PIR HC-SR501}

Pada sensor PIR HC-SR501 terdapat 3 buah pin yang terdiri atas pin vcc, pin vout, dan pin GND (ground). Untuk menghubungkan sensor PIR HC-SR501 dengan board arduino maka pin vout dari sensor PIR HC-SR501 disambungkan pada pin 2 dari board arduino. Sedangkan agar sensor PIR HC-SR501 dapat beroperasi maka pin vcc dan pin GND sensor PIR HC-SR501 masingmasing terhubung ke pin $5 \mathrm{~V}$ dan pin GND pada board arduino.

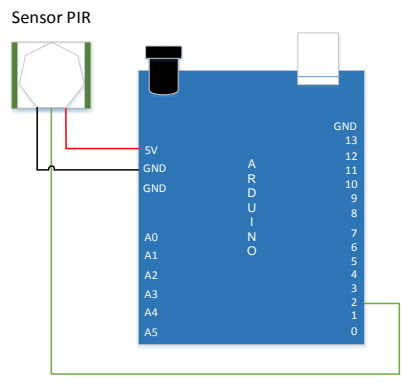

Gambar 10. Rangkaian sensor PIR dengan Board Arduino Uno 


\section{Pengujian sensor PIR HC-SR501}

Pengujian sensor ini dilakukan untuk mengetahui apakah sensor ini sesuai karakteristiknya yakni hanya dapat mendeteksi keberadaan manusia.

Tabel 2. Hasil pengujian sensor PIR HC-SR501 pada manusia

\begin{tabular}{cc}
\hline Jarak $(\mathrm{m})$ & Mendeteksi \\
\hline 1 & Ya \\
\hline 2 & Ya \\
\hline 3 & Ya \\
\hline 4 & Ya \\
\hline 5 & Ya \\
\hline 6 & Ya \\
\hline 7 & Ya \\
\hline 8 & Tidak
\end{tabular}

Pada Tabel 2 telah dapat dilihat sensor dapat mendeteksi manusia. Pada jarak 1 meter sampai dengan 7, sedangkan pada jarak 8 meter sensor sudah tidak dapat lagi mendeteksi. Ini sudah sesuai dengan spesifikasi sensor bahwa sensor dapat mendeteksi manusia sampai jarak 7 meter.

Pendeteksian menggunakan hewan dapat dilihat pada tabel 3 dimana dicoba hewan yaitu kurakura, anjung dan cicak

Tabel 3. Hasil pengujian sensor PIR HC-SR501 pada hewan

\begin{tabular}{ccc}
\hline Nama Hewan & Jarak $(\mathrm{cm})$ & Mendeteksi \\
\cline { 2 - 3 } Kura-Kura & 50 & Tidak \\
\hline \multirow{2}{*}{ Anjung } & 100 & Tidak \\
\hline \multirow{2}{*}{ Cicak } & 50 & Tidak \\
\hline & 100 & Tidak \\
\hline & 50 & Tidak \\
\hline
\end{tabular}

Pada Tabel 3 dapat dilihat bahwa sensor tidak dapat mendeteksi kura-kura, anjing dan cicak walaupun pada jarak $50 \mathrm{~cm}$. Dari tabel 2 dan 3 dapat disimpulkan bahwa sensor ini sudah sesuai dengan tujuan yang diharapkan.

\section{Rangkaian Arduino dengan Sensor Api}

Sensor api terdiri atas 4 pin yaitu AO, DO, GND dan Vout. Pin AO merupakan keluaran dari sensor secara analog sedangkan pin DO merupakan keluaran dari sensor secara digital untuk input pada board arduino. Untuk perancangan system dipilih pin DO sebagai masukan untuk bord arduino agar dihasilkan pembacaan sensor hanya dalam dua keadaan yaitu ketika ada api dan tidak ada api. Pin DO dari sensor dihubungkan dengan pin 3, pin Vec sensor dihubungkan ke pin 5 Volt arduino dan pin ground GND sensor dihubungkan dengan pin ground arduino. 


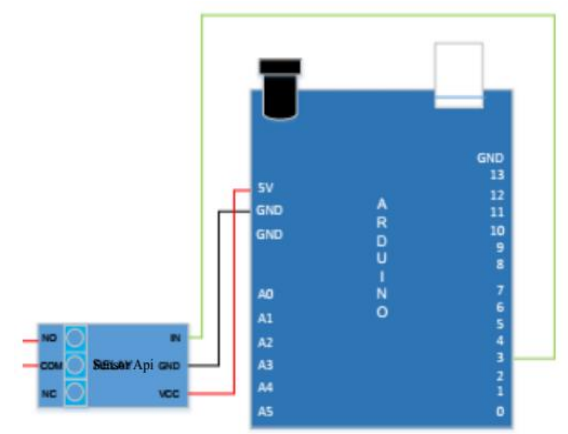

Gambar 11. Rangkaian sensor Api dengan Board Arduino Uno

\section{Pengujian Sensor Api}

Pengujian sensor api bertujuan untuk melihat apakah sensor dapat mendeteksi cahaya api pada jarak tertentu menggunakan berapa jumlah sumber api serta berapa tegangan pada saat pendeteksian terjadi. Sedangkan untuk mendapatkan cahaya api digunakan batang lilin yang diletakkan tegak lurus terhadap sensor.

Tabel 4. Pengujian sensor api dengan 1 sumber

\begin{tabular}{cc}
\hline Jarak $(\mathrm{cm})$ Deteksi Api & Tegangan (volt) \\
\hline 30 & 0,143 \\
\hline 80 & 5,11 \\
\hline 100 & 5,10 \\
\hline 160 & 5,11 \\
\hline 200 & 5,11 \\
\hline
\end{tabular}

Tabel 5. Pengujian sensor api dengan 2 sumber

\begin{tabular}{cc}
\hline Jarak (cm) Deteksi Api & Tegangan (volt) \\
\hline 30 & 0,143 \\
\hline 80 & 5,11 \\
\hline 100 & 5,10 \\
\hline 160 & 5,11 \\
\hline 200 & 5,11 \\
\hline
\end{tabular}

Tabel 6. Pengujian sensor api dengan 3 sumber

\begin{tabular}{cc}
\hline Jarak (cm) Deteksi Api & Tegangan (volt) \\
\hline 30 & 0,143 \\
\hline 80 & 5,11 \\
\hline 100 & 5,10 \\
\hline 160 & 5,11 \\
\hline 200 & 5,11 \\
\hline
\end{tabular}


Tabel 7. Pengujian sensor api dengan 4 sumber

\begin{tabular}{cc}
\hline Jarak (cm) Deteksi Api & Tegangan (volt) \\
\hline 30 & 0,143 \\
\hline 80 & 5,11 \\
\hline 100 & 5,10 \\
\hline 160 & 5,11 \\
\hline 200 & 5,11
\end{tabular}

Dari hasil pengujian sensor api yang dilakukan, didapatkan bahwa jarak dan jumlah sumber cahaya api turut mempengaruhi hasil pendeteksian cahaya api oleh sensor. Apabila cahaya api yang terjadi dalam intensitas yang kecil, sensor tidak dapat mendeteksi cahaya api tersebut pada jarak yang jauh. Namun jika intensitas cahaya api tersebut besar, maka sensor dapat mendeteksi cahaya api dengan jarak yang lebih jauh lagi.

\section{Rangkaian Arduino dengan Keypad 4x4}

Matrik keypad 4x4 merupakan susunan 16 tombol yang membentuk keypad sebagai sarana input ke mikrokontroler, meskipun jumlah tombol ada 16 tetapi hanya memerlukan 8 jalur port parallel. Keypad ini akan diaktifkan dan dideteksi oleh bit-bit logika dari port-port mikrokontroler. Port 1, 2, 3, 4 pada keypad terhubung dengan pin A0, A1, A2, A3 pada board arduino dan port 5, 6, 7, 8 pada keypad terhubung pada pin 9,8,7,6 pada board arduino.

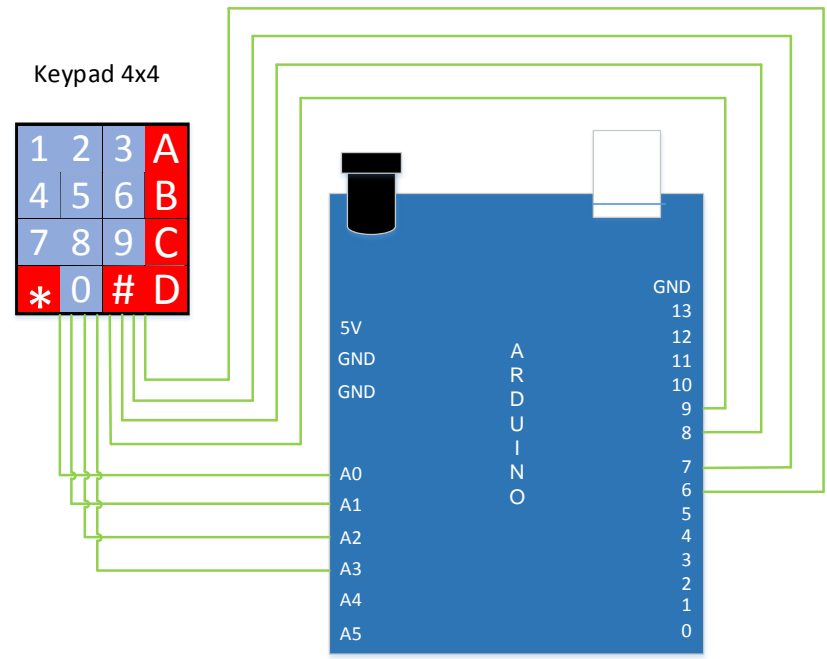

Gambar 12. Rangkaian Keypad 4x4 dengan Board Arduino Uno

\section{Pengujian Keypad}

Pengujian keypad dilakukan dengan cara membuat program kecil untuk menghubungkan keypad, buzzer dan LED warna biru. Saat salah satu tombol keypad ditekan maka buzzer akan berbunyi dan LED biru akan menyala. Pengujian ini dilakukan untuk menyakinkan bahwa input masuk saat tombol keypad ditekan. Pengujian dilakukan dengan menekan semua tombol pada keypad untuk mengetahui apakah semua kondisi tombol keypad dalam kondisi baik atau tidak. 


\section{KESIMPULAN}

Penelitian ini memperlihatkan bahwa sistem pengaman ruangan yang dirancang telah sesuai dengan apa yang diharapkan di mana alam akan berbunyi jika seseorang masuk dalam ruangan tanpa menonaktifkan alarm melaui keypad

\section{DAFTAR PUSTAKA}

[1] `Aulia, Arif. 2010. Sistem Keamanan Pintu Menggunakan Password Berbasis Mikrokontroler AT89S52 (Full). (Online), (Camilo. 2012. Acces control with Arduino + Keypad 4x4 + Servo. (Online), (http://instructables.com/id/Access-control-with-Arduino-Keypad-4x4Servo, diakses 5 April 2014).

[2] Djuandi, Feri. 2011. Pengenalan Arduino. (Online), (http://www.tobuku.com/docs/ArduinoPengenalan.pdf, diakses 23 Maret 2014).

[3] 'Hacks, Cooking. 2012. Tutorial: How to use the PIR Sensor with Arduino. (Online), (http://www.cooking-hacks.com/blog/tutorial-how-to-use-the-pir-sensor-with-arduino, diakses 18 Maret 2014).

[4] Prayuda, Amri Eko. 2012. Prototype Alat Pendeteksi Kebakaran Berbasis Mikrokontroler AT89S51 Dengan Pemberitahuan Via SMS. Yogyakarta: Fakultas Teknik Universitas Negeri Yogyakarta.

[5] Sasongko, Bagus Hari. 2012. Pemrograman Mikrokontroler Dengan Bahasa C. Yogyakarta : Penerbit Andi Publishing. 